\title{
Textos cosmogónico-religiosos de las civi- lizaciones nahuas y españolas: narrativas inestables como ejes simbólicos de sistemas de comunicación socializadores
}

Cosmogonic-Religious Texts of the Nahua, Mixtec and Spanish Civilizations: Unstable Narratives as Symbolic Referents within Socializing Systems of Communication.

Cecilia Brain

University of Western Ontario, Canadá

cbrain@uwo.ca

Resumen • En la España del siglo XVI, las narrativas cosmogónico-religiosas se mantenían, físicamente, usando el sistema alfabético romano. Entre los nahuas y mixtecas, estas historias se mantenían usando un sistema pictográfico. Este artículo discutirá el tema de las tecnologías de escritura, teniendo en cuenta que estas tecnologías y los textos que se basan en ellas, son parte de un sistema de transmisión cultural de información a una población. Este análisis nos permitirá analizar hasta qué punto estas narrativas son necesarias y hasta qué punto son referentes simbólicos en procesos de transmisión de información socializadora, en que las narrativas están cambiando constantemente.

Palabras clave: cosmogonía, historia, comunicación, teatro, sermón.

Abstract • Abstract In the Spain of the 16th Century, cosmogonic-religious narratives were physically maintained using the alphabetic system. Conversely, the Nahua and Mixtecs of Mesoamerica kept their narratives using a pictographic system. This article will approach the issue of writing technologies from the perspective that writing systems and texts are part of a broader system of transmission of cultural information to the population. This type of analysis will allows us to discuss the degree to which these physical records are necessary to the transmission of socializing messages and to what extent they are symbolic referents for a much broader and complex transmission system of socializing information, in which narratives are being transformed constantly.

Keywords: Cosmogony, History, Communication, Theatre, Sermon. 
Mucho se ha dicho desde el contacto inicial de las civilizaciones Mesoamericanas y la civilización española sobre la superioridad de la escritura alfabética romana para archivar información sobre la historia y la religión, en contraste con el sistema pictográfico empleado por los nahuas. El argumento principal se puede resumir diciendo que el sistema de comunicación pictográfico no materializaba una narración estable. Valga como ejemplo esta afirmación de Motolinia en 1541: “...y a causa de no tener letra, sino caracteres, y la memoria de los hombres ser débil y flaca, los viejos de esta tierra son varios en declarar las antigüedades y cosas notables de esta tierra.” (1985: 99). El pictograma, al no ser un equivalente fonético del habla (como la escritura alfabética, cuya lectura permite la repetición de un mismo discurso oral), no permitiría una transmisión exacta de la historia. El otro lado de esta idea establece que la escritura alfabética romana conlleva el elemento de la veracidad. Mendieta, otro cronista español, opina que un nativo que pueda leer la Biblia y los libros de los doctores sagrados en latín será capaz de entender por sí mismo qué bien fundadas estaban las creencias de los españoles:

Mas al fin prevaleció la razón verdadera de que era justo que a lo menos algunos de estos naturales entendiese en alguna manera lo que contiene la sagrada Escritura, y los libros de los sagrados doctores, así para que ellos mismos se fijasen y fortaleciesen más de veras en las cosas de nuestra santa fe, como para que pudiesen satistacer a los otros indios de cuan diferentemente íbamos fundados los cristianos en lo que creemos y seguimos, de lo que cuan y los demás gentiles habían creído y seguido, sin fundamento, ni camino, ni rastro de alguna verdad (1973: v.2 40).

Acosta resume mejor este prejuicio hacia el sistema pictográfico en la siguiente cita: "Pero porque sus figuras y caracteres no eran tan suficientes como nuestra escritura y letras, por eso no podían concordar tan puntualmente en las palabras, sino solamente en lo sustancial de los conceptos" (2002: 384). La conclusión habitual de estas comparaciones entre el sistema pictográfico y el alfabético es que la información contenida en los textos mesoamericanos era minusvalorada por los españoles. ${ }^{1}$

Varios teóricos de la segunda mitad del siglo XX han compartido estas apreciaciones. Gelb (1969), por ejemplo, cataloga el sistema de escritura mexica como un "limited system" entre los precursores de la escritura.

No matter how elaborate in form the beautiful manuscripts and stone inscriptions of the Aztecs and Mayas may appear, in inner structure they are not on a much higher level of development than the primitive systems of North America and Africa. What can be clearly understood in the Central American inscriptions are first and above all the mathematical and astronomical systems of notations. Outside of these, some inscriptions or parts of inscriptions are understandable but only in the sense that the North American pictures are per se intelligible without the conveyance of any linguistic form ${ }^{2}(51)$.

No todas las opiniones de los españoles en el siglo XVI están de acuerdo. Zorita arguye que las diferencias en las relaciones no son sólo por la falta de letras y escritura sino tambien por la falta de interpretes y porque sus historias se mantenían en pinturas que, en su mayoría, habían sido destruidas y cuyos lectores habían fallecido con el tiempo (1993: 9).

"No importa cuan elaborados en forma puedan parecer los hermosos manuscritos e inscripciones en piedra de los Aztecas y Mayas, su estructura interna no posee un nivel de desarrollo mucho más elevado que el de los sistemas primitivos de Norteamérica y África. Lo que se puede comprender claramente de las inscripciones
La escritura, según Gelb, debe ser fonética y concluir, naturalmente en el sistema alfabético que implementaron los griegos (183-184 y 190-205). Ong (1988) arguye que el sistema de los indígenas americanos no llegó a ser un "true script because the code remained too unfixed"3 (86) y que en algún momento, el único sistema pictográfico bien desarrollado que existe en el mundo moderno, el chino, tendrá que darle paso al sistema alfabético ya que éste es más eficiente y más democrático, al ser más fácil de enseñar y difundir (87). Por otra parte, para Goody (1975), la escritura: "must objectify speec [...] In this material

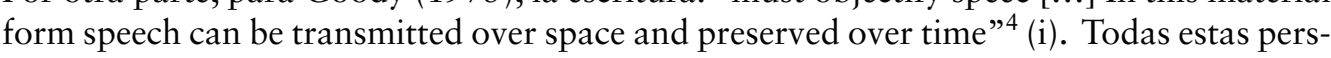
pectivas tienen en común el hecho de equiparar el nivel de eficiencia de una tecnología de escritura con la capacidad de ésta para conservar un discurso oral. ${ }^{5}$ Además, todas estas definiciones coinciden en separar el sistema de escritura de su función como parte de un sistema de comunicación.

Este artículo abarcará el tema partiendo del principio de que los sistemas de escritura y sus productos, los textos, independientemente de su formato pictográfico o alfabético, son parte de todo un sistema social de transmisión de información socio-cultural en una comunidad, sistema que incluye los textos y las varias formas en que se transmite la información a la población. Para ello, se usará como ejemplo el caso específico de los textos cosmogónico-religiosos, es decir, se procederá a un cambio en la escala desde la cual estudiamos el tema de tal manera que nos concentremos en la difusión social de estos textos a nivel social. En este sentido, el objetivo principal de este artículo es analizar, comparándolas, las transformaciones a las que son expuestas la Biblia para los españoles o las narrativas mito-históricos entre los nahuas. Primero, se tendrá en cuenta que este tipo de narración sufre transformaciones temporales que son intergeneracionales y transculturales. Estas transformaciones son el resultado de errores técnicos en el proceso de conservación o de las necesidades de cada sociedad que las utiliza. Segundo, teniendo en cuenta que incluso en los casos en que la narrativa escrita es relativamente estable, lo que puede ocurrir en un momento histórico dado dentro de una comunidad dada, el proceso de diseminación a la población en general la de-estabiliza. Así, este artículo se aleja de una tradición en la que el foco de la discusión era la capacidad del sistema de escritura entre los nahuas de archivar información y transmitirla sin cambios para poder analizar, comparativamente, la estabilidad de ambos sistemas de escritura en el caso particular de las narrativas cosmogónico-religiosas. Este análisis permitirá discutir hasta qué punto estos archivos físicos son una parte necesaria del proceso de transmisión de mensajes socializadores y hasta qué

Centroamericanas son en primer lugar y por sobretodo los sistemas de notación matemática y astronómica. Centroamericanas son en primer lugar y por sobretodo los sistemas de notacion matemática y astronómica.
Fuera de estos, algunas inscripciones o partes de ellas son comprensibles solo en el sentido en que las pinturas Norteamericanas lo son per se, sin transmisión de ninguna forma lingüística”. (Gelb, p. 51). [Trad. Texto original en Inglés]

"Verdadera escritura porque el código se mantuvo muy inestable". [Trad. Texto original en Inglés] "Debe objetivar el habla...en esta forma material el habla puede ser transmitida y preservada en el tiempo". [Trad. Texto original en Inglés]

Algunos de los teóricos mencionados ni siquiera aceptan el término escritura para describir los pictogramas Nahuas y Mixtecas. Más recientemente, Hill Boone (2000), en referencia al sistema pictográfico de los Nahuas y Mixtecas adopta la siguiente definición de escritura: "The communication of relatively specific idea in a conventional manner by means of permanent, visible marks" (30). Esta definición incluye los sistemas de escritura americanos. Hill-Boone, además, plantea que los sistemas de escritura mesoamericanos, como otros sistemas que no intentan recrear la palabra hablada, sistemas conceptuales, por ejemplo los sistemas de signos matemáticos y musicales, tienen características que los hacen más adecuados para la transmisió de cierta clase de información. 
punto son sólo un referente simbólico para un proceso de transmisión de información socializadora mucho más compleja por medio del cual estas narrativas son transformadas constantemente. Además, nos permitirá replantear, dada la inestabilidad y la necesidad de flexibilidad en estas narrativas, la importancia de poder recrear un discurso hablado consistente para la evaluación de los sistemas de escrituras. ${ }^{6}$

\section{HISTORIAS COSMOGÓNICO-RELIGIOSAS EN LA SOCIEDAD}

Una parte central de todos los sistemas de transmisión cultural en todas las civilizaciones, la constituyen las narrativas cosmogónico-religiosas. En España del siglo XVI, estas narrativas se conservaban físicamente en gráficas alfabéticas mientras que entre los nahuas rrativas se conservaban físicamente en gráficas alfabéticas mientras que entre los nahuas
de la misma época se conservaban por medio de un sistema pictográfico. Los textos cosmogónico-religiosos se diferencian de otros textos de las civilizaciones nahuas y española por varias razones. Primero, porque éstos se remiten a un inicio mitológico que, por lo menos en Europa, se considera una ocurrencia verdadera. ${ }^{7}$ Segundo, porque se considera que contienen sabiduría que supera a la actual y, por lo tanto, deben determinar las acciones en el presente. Además, según Pelikan (2005), son un contrato entre los vivos y los muertos, un testamento de nuestros ancestros (4). Los textos mismos contienen referencia a estas ideas. En Leyenda de los soles, una relación escrita alfabéticamente de un códice pictográfico nahua, esto se manifiesta en la primera oración: "Aquí están las consejuelas de la plática sabia" (Anónimo 1945:119). En el Popol Vuh, de los quiché mayas, una civilización no-nahua en Mesoamérica, que según Tedlock (1996:30) constituye una relación alfabética de la interpretación que se hubiera hecho de un pictograma para el público, esta conexión es más evidente. El primer párrafo empieza así: "This is the beginning of the ancient word, here is this place called Quiché. Here we shall inscribe, we shall implant the Ancient Word, the potential source of everything done in the citadel of Quiché, in the nation of the Quiché people" ${ }^{8}(63)$.

En el caso de la Biblia, Pablo escribe:

Por lo cual, también nosotros damos gracias a Dios sin cesar, de que habiendo recibido la palabra de Dios que oísteis de nosotros, recibisteis no palabra de hombres, sino según es en verdad, la palabra de Dios, el cual obra en vosotros lo que creísteis (1 Tesalonicenses 2:13).

Podemos ver un ejemplo de este fenómeno, en práctica, en la obra La perfecta casada de Fray Luis de León, escrita en 1583. Según el autor, este ensayo-manual sobre cómo debe comportarse una mujer casada toma su autoridad "no [de] lo que me enseñó a mí la

Goody (1975) reconoce la falta de flexibilidad de culturas alfabetizadas en relación con aquellas que no tienen escritura. Sin emargo, el argumento tiende a isular las culturas alfabetizadas con las cultur $n$ libro lo cual es problemático dado que las características tecnológicas no son fácilmente diferenciables, en su argumento, de las características de tres religiones que comparten una misma ráz (2).

No es claro si los textos cosmogónicos-religiosos de las civilizaciones Nahuas se consideraban verdad de la misma manera.

Este es el principio de las antiguas historias de este lugar llamado Quiché. Aquí escribiremos y comenzaremo las antiguas historias, el principio y el origen de todo lo que se hizo en la ciudad de Quiché, por las tribus de la nación quiché. "[Trad. Adrían Recinos] <http://www.digi.usac.edu.gt//bvirtual/litgua/

popolvuh/ppvuh.pdf>. experiencia pasada, porque es ajeno a mi profesión, sino [de] lo que he aprendido de las sagradas letras, que enseñanza del Espíritu Santo" (León, 1976: 30). Finalmente, todos estos textos jugaban un papel central para el mantenimiento de una cohesión social similar a la que discute Anderson en Imagined Communities, puesto que permitían que cada ndividuo se percibiera a sí mismo como miembro de un grupo que comparte una religión, una historia y todo un aparato cultural de signos y tradiciones. Además, porque muchas de las festividades comunitarias derivaban de las narrativas en estos textos.

\section{DIFERENCIAS REGIONALES Y TRANSMISIÓN CULTURAL}

Las diferencias regionales en las narrativas cosmogónico-religiosas de los mesoamericanos apoyaban la opinión de los cronistas acerca de que la escritura pictográfica no es estable. En el siglo XVI, Mendieta comenta lo siguiente sobre estas variedades y el método de escritura:

Que aunque esta gente carecía de escritura, no les faltaba para ayuda de la memoria pintura Que aunque esta y caracteres por donde se entendían a falta de letras. Aunque en tiera de Champoton dicen que se hallaron, y que se entendian por ellas, cono nosotros por las nuestras. Verdad es que viniendo los religiosos y otros espanoles seglares curiosos a examinar una misma cosa en diversas provincias, hallaban diversas relaciones, como acaeció en esta materia de saber de dónde vinieron estos naturales mexicanos, y texcucanos, y tlaxcaltecos, sobre lo cual ha habido muy diferentes opiniones (1973:vol.1 87).

Que no existiera una sola versión de la narrativa cosmogónico-religiosa en Mesoamérica es fácil de aceptar. Estas eran comunidades muy diferentes que, aunque estaban en contacto, lo que explica aquellos elementos que tienen en común, tenían diversas necesidades y organizaciones sociales. León-Portilla (1969) explica el desarrollo de las civilizaciones nahuas de la siguiente manera:

The Aztecs, like the Tezcocans [...] and many other groups speaking the Náhuatl language, were actually a strain of a much older culture. Many religious ideas, the social and political organizations, the calendars, writing and many techniques of the arts were received either directly or indirectly by acculturation, through contact with more advanced peoples ${ }^{9}(6)$.

En términos mesoamericanos, León-Portilla atribuye un solo inicio cultural a los toltecas, los mixteca y los mayas. Es decir, las culturas más desarrolladas de Mesoamérica, incluyendo a los aztecas -quienes descienden culturalmente de los toltecas-, provienen de la misma cultura, probablemente la olmeca, como parece probar el hecho de que las inscripciones más antiguas que se han encontrado en México tienen siempre una relación con los olmecas (4-15). En un reciente estudio arqueológico, Pohl, Pope y von Nagy (2002) han demostrado que los elementos básicos de la escritura pictográfica y del calendario de las

"Los Aztecas, al igual que los Tezcocans...y muchos otros grupos hablantes del idioma Náhuatl, fueron en realidad una raza de una cultura mucho más antigua. Gran parte de las ideas religiosas, las organizaciones sociales y políticas, los calendarios, la escritura, y muchas técnicas artísticas fueron adquiridas, ya sea directa o indirectamente, por aculturación a través del contacto con pueblos más avanzados". (León-Portilla, p.6 [Trad. Texto original en Inglés] 
culturas mesoamericanas ya estaban presentes en la cultura olmeca, en 650 B.C. Aunque, como menciona León-Portilla, este proceso de aculturación no implica que los olmecas hayan sido el origen cultural (1996: 8-9), sí demuestra un proceso de transmisión cultural por aculturación en la región. ${ }^{10}$

La interacción cultural descrita en el párrafo anterior se aplica además a las narrativas cosmogónico-religiosas de la región. En Leyenda de los soles, de una civilización nahua, y en el Popol Vuh, del quiché maya, encontramos varios aspectos en común. Entre éstos, los esfuerzos iniciales que hacen los dioses por crear a los seres humanos y sus varios fracasos así como la presencia de 400 jóvenes (en el Popol Vub) o mixcohuas (en Leyenda) y su muerte a manos de seres que tenían poderes relacionados con las fuerzas naturales. Sin embargo, estas historias también varían mucho en su contenido. Esto se debe probablemente al proceso de aculturación al que fue expuesta la narrativa inicial durante el desarrollo de Mesoamérica, a la hibridez que este proceso provoca y a las diferentes necesidades de cada comunidad en un momento específico de su historia. Como un ejemplo, el Popol Vuh (1996) de los quiché mayas explica que los cuatro fundadores de la comunidad provienen de otro lugar, en el este, al que regresan antes de morir (173-175) y que algunos de sus descendientes peregrinan al este, donde reciben títulos de nobleza y la escritura de Tulan (179-180). Es decir, según su texto fundacional, los quiché provienen culturalmente de otra cultura y, puesto que su narrativa cosmogónico-religiosa tiene elementos en común con otras narrativas de la región, es muy probable que la historia original, en forma escrita u oral, haya sido recibida de un antecedente común a todas ellas. Pero los quiché eran también una comunidad central que tenía bajo su poder a otras comunidades; su historia oficial, por lo tanto, reflejaría sus condiciones sociales y se diferenciaría de la historia que recibieron inicialmente. Esto es más evidente en la parte de la narrativa que contiene información sobre los primeros seres humanos viables que pueden crear los dioses. En el Popol Vuh, los primeros cuatro hombres son identificados como quiché (1996:149), aunque el libro de la comunidad en la que se basa la obra, indudablemente, no contendría tal información. ${ }^{1}$

Algo similar ocurre con las narrativas cosmogónico-religiosas judeocristianas. El caso más obvio es el de sumarle el Nuevo Testamento a la narrativa de los israelitas para reflejar mejor los intereses de los cristianos. Esta adición cambia el foco de la narrativa hacia la historia de Jesucristo. Además, el Antiguo Testamento establece que el pueblo hebreo es el elegido por Dios, lo cual es una barrera para la asimilación de otros a la religión cristiana. Para superar esto, Pablo establece en Romanos 11 que, si bien los judíos son el pueblo elegido, han caído en desgracia ante Dios por no tener fe, permitiendo que aquellos que no son judíos suban en la estima de Dios. De la misma manera, en Mateo 16:18-20, se suma el texto necesario para la creación de la iglesia cristiana:

Los fundadores del pueblo quiché son citados en el Popol Vub describiendo cómo la identidad de su comunidad era antes idéntica a la de otra sociedad mesoamericana: "Even though Tohil is his name, he is the same as the god of the Mexican people, who is named Yolcuat and Quitzalcuat. When we divided, there at Tulan, Estos cuatro primeros hombres son también los fundadores de la comunidad, quienes luego regresarán su comunidad original en el Este. La idea de que son realmente los primeros hombres es constantemente contradicha en la historia, pues hay muchas otras comunidades que existen al mismo tiempo que ellos y no son sus descendientes. Por otro lado, si bien dicen ser del Este, su regreso a este es considerado su muerte en el Popol Vuh, lo que nos hace cuestionar si realmente está regresando a su comunidad o si es una forma de decir que murieron.
Yo te digo que tú eres Pedro, y sobre esta piedra edificaré mi iglesia, y las puertas del reino de la muerte no prevalecerán contra ella. Te daré las llaves del reino de los cielos; todo lo que ates en la tierra quedará atado en el cielo, y todo lo que desates en la tierra quedará que ates en la tierra
desatado en el cielo.

Como en el caso de las narrativas mesoamericanas, estos cambios reflejan las intenciones y necesidades del nuevo grupo que las asimila.

Se puede argüir que, en el caso de los cristianos, el Antiguo Testamento se conservó relativamente estable. Sin embargo, en efecto, al añadir el Nuevo Testamento se transformó el significado del Antiguo Testamento. No sólo cambia el texto porque se le añade otra sección, sino que también cambia lo que dice el texto original. En el ejemplo del párrafo anterior, todas las partes del Antiguo Testamento en que se establece que los judíos son el pueblo elegido se vuelven más relativas por la adición del Nuevo Testamento. En el caso de los mormones, se puede ver que no es necesario que las transformaciones se encuentren en un mismo libro ya que el Libro de los Mormones complementa a la Biblia. Los católicos, por su parte, suplementan la Biblia con una serie de textos teológicos de interpretación que se han ido incorporado posteriormente al canon. ${ }^{12}$

Es importante llamar la atención aquí sobre el hecho de que las historias cosmogónicoreligiosas nahuas se diferencian de la judeocristiana en que se les suma constantemente la historia de la comunidad y, por lo tanto, llegan hasta el inicio de la conquista. Algo similar ocurre con los textos judeocristianos, pero éstos no llegan hasta una fecha tan cercana y esto no era un proceso constante, por lo menos, desde varios siglos antes de la conquista. El ejemplo más claro es cuando se suma la historia de Jesucristo, sus apóstoles y la historia temprana de los cristianos al Antiguo Testamento. Es muy probable que también haya ocurrido este proceso en el Antiguo Testamento. Friedman (1997) arguye que hay cinco autores que escriben el texto en un periodo que acapara varios siglos. Entre esos cinco, un redactor compone una sola obra de cuatro textos en los que los autores más recientes han sido influenciados por autores previos. Para citar otro ejemplo español, la Gran e general estoria de Alfonso X se asemeja más a lo que ocurre en Mesoamérica porque intenta combinar la historia más reciente con la historia de la Biblia en un solo libro.

Como hemos visto, en ambas tradiciones de textos cosmogónico-religiosos existe la posibilidad de transformaciones tanto por aculturación como por cambios en el medio ambiente de una misma cultura. Y esto parece ocurrir con independencia de la tecnología de escritura que se utiliza en cada caso. Ahora bien, hay otros elementos, más técnicos, que contribuyen a ciertos cambios en el contenido de textos y que nacen de la necesidad de transcribir, traducir y modernizar el lenguaje de estas narrativas.

\section{LA ESTABILIDAD DEL TEXTO EN SU MEDIO FÍSICO: TRANSCRIPCIÓN, TRADUC- CIÓN Y MODERNIZACIÓN}

En la primera mitad del siglo XVI, existían tantas versiones en latín de la Biblia que el Concilio de Trento encontró prudente establecer la versión Vulgata como la única auténtica. Las razones del concilio muestran la arbitrariedad de la selección: "that the said old and 
vulgate edition, which by the lengthened usage of so many years, has been approved of in the church, be [...] held authentic"13 (1848: 20). El Concilio no pudo decretar que todas las versiones debían ser exactamente iguales y se contentó con que fuesen impresas "in the most correct manner possible"14 $1848: 21)$. De lo que se trata aquí, es de conseguir que las diferentes versiones en latín se mantuvieran relativamente uniformes en su contenido ya que era imposible controlar todos los problemas que podían resultar del proceso de trascripción. Un siglo antes, cuando la imprenta todavía no había sido inventada, cada Biblia debía ser escrita a mano, lo que implicaba que todos los textos eran diferentes entre sí.

En términos de traducción, en un estudio sobre las diferentes versiones de la Biblia en inglés, Kubo y Specht argumentan que ninguna traducción puede ser final por: (1) el descubrimiento de nuevos manuscritos del Viejo y del Nuevo Testamento; (2) un mejor entendimiento del significado de palabras y oraciones en las lenguas de los manuscritos; (3) los constantes cambios que ocurren en el lenguaje inglés (1983:17-20). Es decir, los procesos de traducción y modernización, crean múltiples versiones de la misma historia.

Cabe preguntarse, por tanto, hasta qué punto ocurrían cambios por procesos de trascripción, traducción y modernización del lenguaje (pictográfico y hablado) en Mesoamérica. Como menciona Marcus (1992:13), muchos de los textos pictográficos precolombinos que encontraron los españoles son considerados copias de copias. Si bien, la escasez de textos precolombinos hace difícil establecer cómo ocurrió este proceso, hay algunos puntos que vale la pena considerar. Primero, no hay porqué asumir que los mesoamericanos hayan tenido una mayor habilidad para prevenir errores de trascripción y ya sabemos que ni siquiera los esfuerzos de un aparato burocrático como el de la Iolesia Católica, obsesionado con prevenir esos errores en la Biblia, lo logró conseguir. Segundo, los diferentes sistemas de escritura se prestan a distintos errores y cambios en el momento de transcribir, traducir y modernizar el texto. Tercero, los pictogramas podían ser utilizados en varias comunidades, independientemente del lenguaje que se hablaba en ellas, lo que implica que los problemas de traducción no eran comparables a los de traducciones de la Biblia latina a lenguajes europeos. Finalmente, si la historia cosmogónica-religiosa de los mayas y los nahuas tiene un mismo origen, el desarrollo del sistema fonético silábico en las civilizaciones mayas probablemente conlleva o una transformación completa a otro sistema de escritura o una hibridez que no por eso deja de constituir un cambio substancial. Hoy no existe una copia del Popol Vuh precolombino, pero como menciona Tedlock, se pueden encontrar imágenes que representan varias partes de la historia inscritas en piedra y en decoraciones de artefactos. ${ }^{15}$ En éstos se puede ver una combinación del sistema pictográfico y las gráficas silábicas que es diferente al del sistema puramente pictográfico de otras culturas mesoamericanas, incluyendo las nahuas. Es decir, en la región los cambios en los sistemas de escritura a afectan la narración y, por lo menos en el caso maya, los errores en la parte silábica se deben de haber aproximado más a los errores del sistema alfabético-romano. Si bien el ejemplo anterior no se aplica directamente a la civilización nahua, todo sistema de escritura, como todo lenguaje, evoluciona y esta evolución probablemente conllevó una modernización en las gráficas que narran la historia. "Que esta misma antigua y vulgata edición que está aprobada por el largo uso de tantos siglos en la Iglesia
misma, sea tenida por auténtica". Las Sagradas Escrituras, sesión IV, celebrada el 8 de abril de 1546. Biblioteca electrónica cristiana -BEC- VE Multimedios ${ }^{\mathrm{TM}}$. $<$ http: $/ /$ multimedios.org/docs/d000436/ p000001.htm>.

"De la manera más correcta posible". Ibid.

Por ejemplo, ver la imagen en la edición del Popol Vuh de Tedlock (1996: 40).
En los párrafos anteriores hemos mostrado que los textos cosmogónico-religiosos de España y Mesoamérica están expuestos a cambios por procesos de aculturación, por los procesos político-sociales de cada comunidad y por problemas de trascripción, traducción y modernización. Es decir, el texto en sí se transforma y esto ocurre en ambas civilizaciones, independientemente del sistema de escritura que se utiliza para conservar las narrativas físicamente. Otra clase de trasformación es la que ocurre durante el proceso de transmisión del texto cosmogónico-religioso a la población en general. Es decir, ¿cómo entiende la sociedad en general el texto cosmogónico-religioso?

\section{EL TEXTO COSMOGÓNICO-RELIGIOSO EN SU COMUNIDAD: TRANSMISIÓN}

Para empezar este análisis, hay que establecer que los textos cosmogónico-religiosos son una parte central de la historia oficial religiosa en cada sociedad y que esta historia oficia es en sí una parte central del sistema político-social. En este sentido, si bien los procesos que ya hemos discutido en este artículo pueden transformar los textos significativamente con el tiempo, se puede argüir que una cultura tiene una historia oficial relativamente estable en términos de los textos físicos que las instituciones religiosas y políticas mantienen y de las historias que diseminan al resto de la sociedad, basándose en una interpretación controlada de estos textos. Por otro lado, la sociedad en general no tenía acceso a los textos cosmogónico-religiosos porque eran analfabetos (en el caso de España) o no podían leer los pictogramas (en el caso nahua) y no era económicamente posible que cada individuo tuviese su propia copia del texto cosmogónico-religioso. Este público era, entonces, un receptor aural y visual, pero no lector, de las representaciones de las narrativas cosmogónico-religiosas.

En el catolicismo, la Iglesia controla la historia oficial y es el último eslabón para resolver dudas sobre la Biblia y su interpretación. Como vimos anteriormente, este control de la Biblia no era dependiente de la escritura en sí, porque sí existían varias versiones del libro y éste se modificaba constantemente. La permanencia de libros previos sólo creaba más versiones que comparar. El control de la Biblia dentro de una comunidad es entonces el resultado del uso social que se hace de la tecnología.

Sabemos que en la cultura nahua también había cierto nivel de control. Como en España, sólo un grupo selecto de individuos podía leer el texto cosmogónico-religioso. Bierhorst (1992) afirma que aproximadamente en 1430 la elite azteca quemó varios códices reemplazándolos con códices que exaltaban a los mexica por encima de otros pueblos (i). Como veremos a continuación, independientemente del control que se intenta ejercer sobre la narración, la historia se transmite de múltiples formas y en múltiples narrativas al resto de la sociedad.

En el caso de la cultura nahua, la historia oficial se difundía mediante "lectores" de los pictogramas, quienes creaban una narrativa oral que interpretaban con el acompañamiento de gestos y movimientos corporales delante de la comunidad. Como vimos anteriormente, los pictogramas se consideraban una pista mnemónica para un discurso oral representado. La inestabilidad de la memoria, por lo tanto, explicaría que los ancianos de los que habla Motolinía no se puedan poner de acuerdo sobre los detalles de su historia. En realidad, es muy difícil establecer qué nivel de estabilidad tenían estas versiones de la historia oficial. Gruzinski (1993:13) arguye que los pictogramas no eran simplemente pistas mnemónicas, sino que decían algo. Hill-Boone (2000: 22) explica que, como textos legales, eran 
consultados para resolver disputas. Alonso de Zorita describe el uso de pinturas para la administración del calpulli:

Este principal tiene cuidado de mirar por las tierras del calpulli y defenderlas, y tiene pintadas las suertes que son, y las lindes, y adónde y con quién parten términos y quién las labra, y las que tiene cada uno; y cuáles están vacas, y cuáles se han dado a españoles y quién y cuándo y a quién las dieron, y van renovando siempre sus pinturas según los sucesos, y se entienden muy bien por ellas...(1993: 34).

Por otro lado, el que la elite azteca haya quemado textos supone o que la eliminación de éstos implicaba una pérdida de información archivada que no era fácilmente recuperable por la tradición oral y/o que esta censura estaba acompañada de un represión de diálogo que por lo menos transformó la tradición oral.

De acuerdo con Van der Loo (1994: 84), en la sociedad nahua, aunque la representación de un pictograma varía dependiendo del intérprete, el significado esencial se mantiene. Gruzinski señala que, aunque los pictogramas eran censurados, existía cierta libertad de interpretación a la hora de representar la historia (1993: 10). Las diferencias en las representaciones podrían haber sido simples diferencias de interpretación, basada en las necesidades políticas de cada intérprete o grupo social en un momento histórico dado. Es decir, se moldeaba la historia a las necesidades ideológicas de cada lugar y cada "presente". Marcus (1992), por su parte, arguye que en Mesoamérica la escritura en sí era una herramienta política: "writing was used to make public and permanent a whole series of messages that the hereditary leaders of society deemed important" ${ }^{16}(4)$. Los encargados de representar la información contenida en los pictogramas nahuas estaban creando múltiples narrativas que reflejaban las cambiantes necesidades de su sociedad. Si bien -en un momento histórico específico- estas narrativas eran diferentes las unas de las otras, se deben de haber mantenido relativamente estables a lo largo del tiempo para inculcar aquellos elementos que eran considerados esenciales dentro del contexto social. Por ejemplo, en Leyenda de los soles sus hermanos matan al héroe Mixcoatl. En Histoyre du Mechique son tres de sus hijos quienes lo matan al enterarse de que él prefiere a su hijo Quetzalcóatl. Aunque los detalles son diferentes, el elemento de traición domina esta historia en ambos casos y es la causa de la venganza de Quetzalcóatl, quien se vuelve un héroe por sus propias hazañas y no ya las de su padre. ${ }^{17}$ Es decir, había una interacción entre la intención política, el contexto social y el sistema oral-pictográfico.

Ahora bien, en España, la Biblia, una narración o serie de narraciones (muchas de ellas varias versiones de los mismos sucesos) y los libros teológicos del canon constituían la historia oficial sagrada. Pero la sociedad en general no tenía acceso directo a estas narrativas. Como en Mesoamérica, un número limitado de individuos transmitía esta información al pueblo en general. Esto es particularmente relevante cuando la Biblia todavía no había sido traducida a la lengua vernácula. La primera versión fue traducida por encargo

"La escritura era usada para hacer pública y permanente series completas de mensajes que los líderes herederos de la sociedad consideraban importantes" [Trad. Texto original en Inglés].

Es importante notar que he usado una traducción de Histoyre du Mechique que es a su vez una traducción de un texto español y que la obra parece estar escrita por un español, quien se refiere a los indígenas en tercera persona. Para esta comparación, estamos asumiendo que la historia, contada en Histoyre du Mechique es una versión verdadera y no un error de comprensión de parte del escritor o que ocurre por el proceso de traducción. de Alfonso X en 1280 y se publicó como parte de su Gran e general estoria, pero según Catalán (1965:311) y Stavans (2004) esta versión es más bien una paráfrasis de la Biblia Vulgata de San Jerónimo. En el Siglo XV aparecen las primeras traducciones en castellano del Antiguo Testamento y en 1543 la primera traducción del Nuevo Testamento por Francisco de Enzinas. No es hasta 1569 que se escribe la primera traducción de la Biblia entera al castellano. Es decir, hasta el siglo XVI sólo aquellos que sabían leer latín tenían acceso directo al Nuevo Testamento. Para difundir la información del texto, por lo tanto, las narraciones contenidas en ése se debían traducir del latín o griego al español, lo que causaba inestabilidad en las historias. ${ }^{18}$

El sistema más evidente de transmisión oral antes y después de las traducciones de la Biblia era el de los sacerdotes y predicadores, quienes utilizaban sermones que se basaban parcial y muy libremente en historias escogidas de la Biblia. Pero el objetivo de estos predicadores era socializar ${ }^{19}$ a los individuos no trasmitir la narrativa cosmogónico-religiosa exactamente como estaba escrita. Según Noel (1985), en un estudio sobre los predicadores del siglo XVIII en España: "They preached not only about the personal Christian virtues but also about social virtues manifested in the family and, especially, in the economic and political community" 20 (867). Una carta que el predicador Francisco Terrones Aguilar del Caño (1999) le escribió a su sobrino en el siglo XVI para enseñarle cómo predicar dice:

El más substancial documento, y que yo más he procurado guardar en este oficio, es que todo el sermón o la mayor parte de él sea de cosas morales, quiero decir provechosas para las costumbres, reprendiendo vicios, aconsejando, persuadiendo virtudes, convidando al cielo, afeando pecados, amenazando con muerte e infierno, convenciendo los entendimientos con buenas y eficaces razones de que van errados y perdidos...

Es decir, la meta no era inculcar la historia cosmogónica-religiosa, sino usarla para moralizar.

En su carta, Terrones Aguilar del Caño permite entender los elementos que influenciaban la calidad de los sermones de la época. Primero, hay diferentes niveles de habilidad natura y estilo entre los predicadores. Segundo, la Biblia es sólo una de las varias fuentes textuales en las que se basa el sermón y podía constituir una parte mínima del discurso: "Ni estos que decían los enriquecían mucho de Escritura". Otras fuentes eran la teología escolástica, tratados de medicina, leyes y cánones (de historia antigua y humanidades), lecciones de santos así como otros tratados y sermones anteriores. Además, el conocimiento de cada predicador variaba. Es decir, cada predicador utilizaba un archivo de conocimientos diferente, que también incluía los textos cosmogónico-religiosos, para redactar su sermón. Tercero, el predicador debe siempre tener en cuenta las posibles consecuencias de lo que predica. Si bien el autor de esta carta aconseja que uno sea siempre honesto en su predicación, cuenta que muchos predicadores han sido denunciados a la Inquisición sólo por enojar a una persona notable y da ejemplos de situaciones en la Antigüedad en que se ha

18 Aquí cabe preguntarse si era realmente más fácil aprender a leer en otra lengua que descifrar los pictogramas.

${ }_{20}$ "Ellos no solo predicaban acerca de las virtudes cristianas sino también acerca de las virtudes sociales manifestadas en la familia, y especialmente, en la comunidad económica y política". [Trad. Texto original en Inglés] 
castigado a un predicador o se ha forzado la censura: "Yo certifico, como Calificador que he sido de la Inquisición de Granada y en el Consejo, que, si hubiesen los inquisidores de llamar a todos los predicadores que son denunciados por oyentes ruines, no habría quien predicase" (Terrones de Aguilar). Finalmente, hay que intentar ser eficaz para lograr el propósito socializador que se desea, lo que implica que el predicador debe tener en cuenta la naturaleza de su público.

Estos elementos muestran que el discurso que se difundía al pueblo variaba mucho, que estaba influenciado por elementos políticos y por la meta socializadora del predicador, que las historias de la Biblia se transmitían como parte de un sermón que se prestaba de otros textos y, finalmente, que estaba influenciado por la audiencia. En términos comparativos, si bien los oradores nahuas no leían una narrativa en sus pinturas que les permitía repetir exactamente la misma historia a su público, en España, donde en teoría era posible, esto tampoco ocurría; las particularidades del orador, la intervención política y las necesidades tampoco ocurría; las particularidades del orador, la intervención política

La función de la Biblia en sí era la de darle autoridad al sermón y al predicador. Terrones Aguilar de Caño nos cuenta que entre los malos predicadores, se usaba el citar en latín excesivamente porque la audiencia los consideraba eruditos en la Biblia: "[...] dicen con admiración que sabe mucha escritura (y es de memoria)" (Terrones de Aguilar). Terrones se muestra en contra de esta práctica y la de citar capítulos, pero no contra la de citar los nombres de los libros de la Biblia o de los apóstoles para establecer la autoridad de las palabras dichas. Es decir, en términos del contenido del sermón, la Biblia era un texto más que compartía el espacio con los clásicos y las fábulas, pero tenía el lugar privilegiado de ser el único que se consideraba la palabra de Dios. Esto proporcionaba un grado de legitimidad al sermón y al predicador, pues su conocimiento de la Biblia implicaba que conocía mejor el texto sagrado que el público en general.

Otra forma de difundir la información basada en textos cosmogónico-religiosos era el teatro que, generalmente, se representaba en fiestas religiosas. En el caso particular del teatro actores y todo el elenco que representaba la obra para una audiencia. Wardropper (1950 en un estudio de los antecedentes del auto sacramental español, documenta los diferentes cambios que se hicieron a la historia del nacimiento de Jesús Cristo durante el Siglo XVI. Por ejemplo, en la Égloga o farsa del nacimiento de nuestro redemptor Jesucristo de Luca, el ángel que informa a los pastores de la llegada de Jesucristo es eremita. Desde este momento, el ángel será reemplazado por sacerdotes, personajes educados que hablan un castellano mejor que el de los pastores y, en 1521, por la figura alegórica de la fe (1201). En la Farsa Sacramental de Hernán López de Yanguas de 1520 los pastores son los padres de la Iglesia.

Los receptores también influyen la forma en que se presenta la historia. Como en la comunidad nahua, lo importante no son los detalles sino que el mensaje socializador se transmita de la manera más influyente a la audiencia. Por lo tanto, si la audiencia está compuesta de herreros, colmeneros o molineros, un personaje representativo de estas profesiones es incluido en la historia que se representa (Wardropper 1950: 1202). En lo esencial, todas estas historias sobre el nacimiento de Jesús crean un relato muchísimo más amplio que el que está presente en La Biblia. En este sentido, el proceso es muy similar a nahua, en que el sistema pictográfico proporciona un esqueleto de acontecimientos desde el cual se crea una narración. La flexibilidad del sistema pictográfico, en comparación con el texto alfabético, puede permitir una mayor libertad en la narración oral sin que haya una contradicción con el texto.
Esta libertad de un autor de alterar la historia oficial para mejorar la evangelización y la socialización, encontrará su mayor representación en el Auto Sacramental de Calderón de la Barca. En El Gran Teatro del Mundo, por ejemplo, la enseñanza de que cada individuo debe aceptar su posición dentro de la jerarquía social como el deseo de Dios y que, desde esa posición social, debe escoger actuar de una manera caritativa para con los otros, no tiene un elemento correspondiente en ninguna narración bíblica. Lo esencial es evangelizar y socializar y la narración se construye para lograr la mejor transmisión a un público contemporáneo, independientemente de la historia oficial. Bassnet dice que: "Tranformations, or variants, are those changes which do not modify the core of meaning but influence the expressive form" 21 (2002: 33). Bassnett está discutiendo las traducciones en general. En el caso de Calderón de lo que se trata es de una traducción en que "the core of meaning" son conceptos socializadores que no remiten necesariamente a información en la Biblia si no a un "core meaning" que refleja las necesidades de su sociedad.

\section{LA TRADICIÓN ORAL}

Como mencionamos anteriormente, en términos europeos, los textos teológicos que forman parte del canon complementan el texto cosmogónico para formar la historia oficial. Ahora bien, la historia oficial en términos cosmogónico-religiosos en ambas culturas dependía también de una tradición oral oficial. Esto es muy aceptado con respecto a los nahuas. La perspectiva más tradicional es que las historias eran memorizadas por los oradores en sus escuelas especializadas, los calmenac, lo que apoyaba la perspectiva de que estas historias no eran estables en su concepción y difusión. Sin embargo, en Europa también hay un elemento oral. Frente al creciente protestantismo del siglo XV, que decía basarse exclusivamente en La Biblia y rechazaba no sólo la tradición religiosa que no se basaba en La Biblia sino también la interpretación católica del texto, la sesión IV del Concilio de Trento promulgó en 1546 el Decreto sobre las escrituras canónicas, en el cual se establece:

...keeping this always in view, that, errors being removed, the purity itself of the Gospel be preserved in the Church; which (Gospel), before promised through the prophets in the holy Scriptures, our Lord Jesus Christ, the Son of God, first promulgated with His own mouth, and then commanded to be preached by His Apostles to every creature, as the fountain of all, both saving truth, and moral discipline; and seeing clearly that this truth and discipline are contained in the written books, and the unwritten traditions which, received by the Apostles from the mouth of Christ himself, or from the Apostes the from the 作 f of piety, and reverence, afl the books both of the Old and of the New Testament -eeing that one God is the author of both- as also the said tradtions, as well those appertaining to faith as to morals, as having been dictated, either by Christ's own word of mouth, or by the Holy Ghost, and preserved in the Catholic Church by a continuous succession ${ }^{22}(18)$

"Las transformaciones, o variantes, son aquellos cambios que no modifican el núcleo de significado, pero influencian su forma de expresión". [Trad. Texto original en Inglés].

"Proponiéndose siempre por objeto, que exterminados los errores, se conserve en la Iglesia la misma pureza del Evangelio, que prometido antes en la divina Escritura por los Profetas, promulgó primeramente por su propia boca nuestro Jesucristo, hijo de Dios, y Señor nuestro, y mandó después a sus Apóstoles que lo pre- 
Es decir, en ambos casos, la tradición oral era una parte importante del sistema de comunicación y complementaba al texto. La flexibilidad de esta tradición oral, más que una falta de eficiencia o una inestabilidad, es un mecanismo importante para que las narrativas del sistema de comunicación cultural puedan ser modificadas de acuerdo con las necesidades políticas y sociales de cada sociedad.

\section{INTERPRETACIÓN}

Todos los procesos de transmisión de la narrativa cosmogónica-religiosa que hemos discutido están influenciados por la interpretación. En su teoría sobre la recepción, Jauss argumenta que el significado de un texto proviene de la interacción que el lector tiene con ese texto. Esta interpretación está basada en una experiencia persona, que es una función del contexto social al que el individuo ha sido expuesto. Es decir, todas las interpretaciones sobre la narración y el significado de la historia dependen de los contactos previos con la historia oficial, las narrativas derivadas de la historia oficial y otras narrativas orales que a su vez se derivan de textos u otras narrativas orales. Se le suma a esta lista el resto de información cultural que recibe cada individuo de su contexto social. En ese sentido, las historias cosmogónico-religiosas que circulan dentro de la sociedad cambian continuamente, creando diferentes significados que reflejan los cambios introducidos por los intérpretes y la necesidades que surgen del contexto social. Con respecto a la Biblia, Kling explica:

Several consequences arise from detaching biblical texts from their application in diverse historical contexts. For one, such neglect creates a false impression that sacred texts are static, stable entities, that they function independently of time and space. But this has never been so. First, the Bible itself is embedded in a variety of cultural contexts and reflects the influence of its social settings. Second, because of the changing nature of life itself, nearly every generation of Christians has reinterpreted Scripture (with varying degrees of selfawareness) in order to make the Bible relevant to their concerns ${ }^{23}(4)$.

Ahora bien, como hemos discutido, la narrativa cosmogónico-religiosa pasa por un proceso interpretativo por parte de este individuo, responsable de difundir la historia para lograr un proceso socializador. El público, que sólo tiene acceso a las representaciones de

dicasen a toda criatura, como fuente de toda verdad conducente a nuestra salvación, y regla de costumbres; considerando que esta verdad y disciplina estan contenidas en los libros escritos, y en las tradiciones no escritas, que recibidas de boca del mismo Cristo por los Apóstoles, o enseñadas por los mismos Apóstoles inspirados por el Espiritu Santo, han llegado como de mano en mano hasta nosotros, siguiendo los ejemplo de los Padres católicos, recibe y venera con igual afecto de piedad y reverencia, todos los libros del viejo y nuevo Testamento, pues Dios es el unico autor de ambos, así como las mencionadas tradiciones pertenecientes a la fe y a las costumbres, como que fueron dictadas verbalmente por Jesucristo, o por el Espíritu Santo, y conservadas perpetuamente sin interrupción en la Iglesia catolica . Las Sagradas Escrituras, sesión $\mathrm{K}$, cele"V

históricos. Por ejemplo, tal deson al separar los textos bíblicos de su aplicación en diversos contexto entidades estables que funcionan independientemente del tiempo y espacio. Pero esto nunca ha sido aś. En primer lugar, la Biblia en sí está incorporada en una variedad de contextos culturales y refleja la influencia de su entorno social. En segundo lugar, debido a la naturaleza cambiante de la vida misma, casi todas las generaciones de cristianos han reinterpretado la Escritura (con distintos grados de autoconciencia) para hace la Biblia relevante a sus intereses". [Trad. Texto original en Inglés] estos intermediarios, también interpreta estas representaciones. Las representaciones en sí contienen elementos de la narrativa cosmogónico-religiosa de los textos físicos, pero, como hemos visto, éstas no son ni lecturas exactas del texto, ni tienen por qué ser una parte significativa del mismo, sino por el contrario, son elementos que intentan dar autoridad al mensaje mora de los intermediarios. En este sentido, el público crea su propia historia cosmogónica-religiosa a partir de las varias interacciones que ha tenido con las representaciones de intermediarios y de otros miembros del público, quienes, al asimilar las ideas que se consideran parte de la historia cosmogónico-religiosa, las repiten como autores de otras interpretaciones y como conversadores. La Figura 1 muestra un esquema resumen del proceso por el que el público en una sociedad entiende la narrativa cosmogónica-religiosa en una sociedad dada. El proceso no sólo es de arriba abajo, todos los niveles se influencia mutuamente ya que todos acaban afectando la construcción mental de los individuos sobre la historia.

\section{Transmisión de la historia religiosa}

\begin{tabular}{|c|c|c|c|}
\hline $\begin{array}{l}\text { Historia } \\
\text { Oficial }\end{array}$ & $\begin{array}{l}\text { Texto cosmogónico- } \\
\text { religioso }\end{array}$ & $\begin{array}{l}\text { Textos } \\
\text { de apoyo }\end{array}$ & $\begin{array}{l}\text { Tradición } \\
\text { oral }\end{array}$ \\
\hline \multirow{3}{*}{$\begin{array}{l}\text { Representaciones } \\
\text { para el público en } \\
\text { general }\end{array}$} & \multicolumn{3}{|c|}{ Interpretación } \\
\hline & \multicolumn{3}{|c|}{$\begin{array}{l}\text { Representaciones visuales-orales que incluyen } \\
\text { información sobre la narrativa cosmogónico-religiosa }\end{array}$} \\
\hline & \multicolumn{3}{|c|}{ Interpretación } \\
\hline Público & $\left\{\begin{array}{c}\text { Multiples const } \\
\text { narrativa cosm } \\
\text { re-transmiten }\end{array}\right.$ & $\begin{array}{l}\text { iones persc } \\
\text { nico-religic } \\
\text { ndividuo a }\end{array}$ & $\begin{array}{l}\text { de la } \\
\text { e se } \\
\text { duo }\end{array}$ \\
\hline
\end{tabular}

\section{CONCLUSIÓN}

Lo que encontramos es que los dos sistemas de transmisión de comunicación, el nahua y el español, parten de un texto que es parte de una historia oficial, pero en ningún caso la transmiten aquellos encargados de "evangelizar" como una lectura exacta del texto. El acto de recepción por el público, en general, es diferente que el de un lector con acceso directo La Biblia o a los códices en pictogramas, para quienes la variación proviene directament del contacto interpretativo que ellos tienen con la obra. Uno o varios intérpretes traducen la historia oficial a una versión que es relevante al contexto social y que logra el propósito didáctico o evangelizador que se propone. Esta versión es nuevamente interpretada por el público receptor. Si bien los escritores de obras del teatro religioso español creaban historias físicamente más duraderas que las de los que median las narrativas nahuas, quienes transmitían la historia oralmente, éstas se transmitían al público en representaciones teatrales que no tenían esa duración física.

Esto nos lleva a las siguientes conclusiones: primero, ambos sistemas de comunicación, el español y el nahua, carecían de estabilidad total en su narración, lo que obliga a replantear 
la autoridad narrativa que se le atribuía al sistema europeo basado en la superioridad de la escritura alfabética romana de almacenar una narrativa oral. La flexibilidad del sistema pictográfico puede haber constituido una ventaja para la difusión de este tipo de textos dada la función social y política éstos. Aquí, además, no se debe ignorar que la tradición imaginativa, mediante el uso del teatro, en España coexiste con la humanística (basada en el texto). Segundo, la narración es un método didáctico muy importante en ambas civilizaciones que se valida mediante el uso de narrativas derivadas de los textos cosmogónico-religiosos. Finalmente, comparaciones entre los diferentes sistemas de transmisión de comunicación deben tener en cuenta no sólo las diferencias, sino también aquellos elementos que los hacen similares.

\section{REFERENCIAS}

Acosta, José de. (2002). Historia natural y moral de las Indias. Ed. José Alcina Franch. Madrid: Dastin.

Alfonso X. (2001). General estoria. Madrid: Fundación José Antonio de Castro.

Anderson, Benedict. (1991). Imagined Communities. New York \& London: Verso.

Anónimo. (1945). Códice Chimalpopoca: Anales de Cuaubtitlan y Leyenda de los soles. Trans. Primo Feliciano Velásquez. México. Imprenta Universitaria.

Anónimo. (1965). "Histoyre du Mechique”. En: Teogonía e historia de los mexicanos. Ed. Garibay Kintana. México. Porrúa.

Anónimo. (1996). Popol Vuh. Trans. Dennis Tedlock. New York, London, Toronto \& Syndney: Simon \& Schuster.

Bassnett, Susan. (2002). Translation Studies. London \& New York: Routledge.

Bierhorst, John. (1992). History and Mythology of the Aztecs: The Codex Chimalpopoca. Tucson: The University of Arizona Press.

Calderón de la Barca, Pedro. (1981). El Gran Teatro del Mundo. Ed. Domingo Ynduráin. Madrid: Alhambra.

Catalán, Diego. (1965). "La Biblia en la literatura medieval española”. En: Hispanic Review. 33.3: 310-318.

Council of Trent, The. (1848). The cannons and decrees of the Sacred and oecumenical Council of Trent. Trans. J. Waterworth. London: Dolman.

Fernández, Lucas. (1929). Farsas y églogas al modo y estilo pastoril y castellano. Ed. Emilio Cotarelo y Mori. Madrid: RAE.

Friedman, R.E. (1997). "Who Wrote the Bible?” San Francisco, CA: Harper Collins.

Gelb, Ian J. (1969). A Study of Writing. Chicago \& London: the U of Chicago P.

Goody, Jack. (1975). Literacy in Traditional Societies. Cambridge: Cambridge UP.

Gruzinski, Serge. (1993). The conquest of Mexico: the incorporation of Indian societies into the Western world, $16^{\text {th }}-18^{\text {th }}$ centuries. Trans. Eileen Corrigan. Cambridge: Polity Press.

Hill-Boone, Elizabeth. (2000). Stories in Red and Black. Austin: University of Texas Press.

Jauss, Hans Robert. (2001). "From Literary History as a Challenge to Literary Theory". En: The Norton Anthology of Theory and Criticism. Ed. Vincent B. Leitch. New York \& London: W. W. Norton \& Company: 1547-1564.

Kling, David William. (2004). The Bible in history: how the texts have shaped the times. New York: Oxford University Press.
Kubo, Sakae, and Walter F. Specht. (1983). So many versions? Twentieth century English versions of the Bible. Rev. and enl. ed. Grand Rapids: Zondervan.

León, Fray Luis de. (1976). La perfecta casada. México: Aguilar.

León-Portilla, Miguel. (1969). Pre-Columbian Literatures of Mexico. Trans. Grace Lobanov and Miguel León-Portilla. Norman: University of Oklahoma Press.

López de Yanguas, Fernán. (1967). Farsa sacramental. Fernando González Ollé. Obras dramáticas. Madrid: Espasa-Calpe.

Marcus, Joyce. (1992). Mesoamerican Writing Systems: Propaganda, Myth, and History in Four Ancient Civilizations. Princeton, NJ: Princeton University Press.

Mendieta, Jerónimo de. (1973). Historia eclesiástica indiana. Ed. Francisco Solano y PérezLila. 2 vols. Madrid: Ediciones Atlas.

Motolinía, Toribio de Benavente. (1985). Historia de los indios de la Nueva España. Ed. Georges Baudot. Madrid: Clásicos Castalia.

Noel, Charles C. (1985). "Missionary Preachers in Spain: Teaching Social Virtue in the Eighteenth Century". En: The American Historical Review. 90.4: 866-892.

Ong, Water J. (1988). Orality and Literacy. London and New York: Routledge.

Pelikan, Jaroslav Jan. (2005). Whose Bible is it?: A history of the Scriptures through the ages. New York: Viking.

Pohl, Mary E. D., Kevin O. Pope and Christopher von Nagy. (2002). "Olmec Origins of Mesoamerican Writing.” En: Science. Vol 298.

Stavans, Ilan. (2004). "La imaginación restaurada". En: Anuario del Instituto Cervantes. Obtenido el 4 de mayo de 2007 desde: <http://crc.cervantes.es/obref/anuario/anuario_04/stavans/default.htm>

Tedlock, Denis. (1996). “Introduction”. En: Popol Vuh. Trans. Dennis Tedlock. New York, London, Toronto \& Syndney: Simon \& Schuster.

Terrones, Aguilar y Francisco del Caño. (1999). Arte o instrucción... que ha de tener el predicador.. Alicante: Biblioteca Virtual Miguel de Cervantes. Obtenido el 26 de Mayo de 2007 desde: http://www.cervantesvirtual.com/servlet/SirveObras/79160620218137506322202/index.htm

van der Loo, Peter L. (1994). "Voicing the Painted Image". Ed. Elizabeth Hill Boone and Walter D. Mignolo. En: Writing Without Words: Alternative Literacies in Mesoamerican and the Andes. Durham: Duke UP.

Wardropper, Bruce W. (1950). "The Search for a Dramatic Formula for the Auto Sacramental". En: PMLA 65.6:1196-1211.

Zorita, Alonso de. (1993). Los señores de la Nueva España. México: UNAM.

Recepción: jueves 3 de septiembre de 2009 Aceptación: martes 5 de enero de 2010 